\title{
ANALISIS PERBANDINGAN METODE PERBAIKAN TANAH PADA KONSTRUKSI JALAN TOL DI ATAS TANAH GAMBUT
}

\author{
Renaldo Arisugan ${ }^{1}$ dan Aniek Prihatiningsih ${ }^{2}$ \\ ${ }^{1}$ Program Studi Sarjana Teknik Sipil, Universitas Tarumanagara, Jl.Letjen S. Parman No.1 Jakarta \\ renaldo.325170016@stu.untar.ac.id \\ ${ }^{2}$ Program Studi Sarjana Teknik Sipil, Universitas Tarumanagara, Jl.Letjen S. Parman No.1 Jakarta \\ aniekp@ft.untar.ac.id
}

Masuk: 13-07-2021, revisi: 06-08-2021, diterima untuk diterbitkan: 19-08-2021

\begin{abstract}
The increase in the number of vehicles that continues to increase every year makes the burden on the road increase. This is quite interesting and must be watched out for by contractors when building roads, namely so that the road does not experience a decline or collapse. So the bearing capacity of the soil and the settlement of the soil must be considered when building roads. The soil improvement method is one of the things that can be done to reduce or accelerate settlement and increase the carrying capacity. The many methods of soil improvement that continue to develop over time need to be researched and analyzed so that they can be applied effectively to each construction case. This research will discuss suitable and effective soil improvement methods for the construction of toll roads on peatlands. It is hoped that the lowest settlement method will be the best soil improvement method. The best soil method will be sought for the most suitable and most effective specifications for the construction of toll roads on peatlands.
\end{abstract}

Keywords: soil improvement; peatlands; stone column; pile of wood; micropile

\begin{abstract}
ABSTRAK
Pertambahan jumlah kendaraan yang terus meningkat setiap tahunnya menjadikan beban pada jalan meningkat. Hal ini menjadi hal yang cukup menarik perhatian dan harus diwaspadai bagi para kontraktor ketika membangun jalan, yaitu agar jalan tidak mengalami penurunan atau keruntuhan. Maka itu daya dukung tanah dan penurunan pada tanah harus diperhatikan ketika membangun jalan. Metode perbaikan tanah menjadi salah satu hal yang dapat dilakukan untuk mengurangi atau mempercepat penurunan dan meningkatkan daya dukung. Banyaknya metode perbaikan tanah yang terus berkembang seiring berjalannya waktu perlu diteliti dan dianalisis agar dapat diaplikasikan secara efektif untuk setiap kasus konstruksi. Pada penilitian ini akan dibahas mengenai metode perbaikan tanah yang cocok dan efektif pada pembangunan jalan tol diatas lahan gambut.
\end{abstract}

Kata kunci: perbaikan tanah; tanah gambut; stone column; cerucuk kayu; micropile

\section{PENDAHULUAN}

\section{Latar belakang}

Tanah gambut merupakan merupakan tanah kompresif dengan kandungan air dan kadar materi organik yang tinggi. Berdasarkan data Global Wetlands yang diakses pada 5 Februari 2021, Indonesia memiliki lahan gambut terbesar kedua di dunia dengan luas mencapai 22.452.222 hektare (ha). Sedangkan urutan pertama ditempati Brazil dengan luas lahan gambut sebesar 31.075.433 ha. Di Indonesia ada beberapa provinsi dengan tanah gambut yang lumayan luas yaitu, Papua memiliki luas lahan gambut 6.274.046 ha, Kalimantan Tengah memiliki luas lahan gambut 2.691.885 ha, Riau memiliki luas lahan gambut 2.220.890 ha, Kalimantan Barat memiliki luas lahan gambut 1.789.448 ha dan Sumatera Selatan memiliki luas lahan gambut 1.731.766 juta ha, Papua Barat memiliki luas lahan gambut 1.299.854 ha, Kalimantan Timur memiliki luas lahan gambut 970.868 ha serta Kalimantan Utara memiliki luas lahan gambut 594.739 ha (Global Wetlands, 2019).

Melalui rapat terbatas pemerintah pada tanggal 29 April 2019, Bapak Presiden Joko Widodo memutuskan untuk memindahkan ibu kota yang semula berada di Pulau Jawa menjadi di Pulau Kalimantan, lebih tepatnya berada pada wilayah Kalimantan Timur (TEMPO.CO, 2019). Perpindahan ibu kota ke Kalimantan Timur ditujukan untuk mengurangi risiko bencana alam, namun Kalimantan merupakan daerah atau wilayah yang memiliki tanah gambut 
yang cukup luas (selain Sumatera dan Papua). Apabila ibu kota sudah sepenuhnya dipindahkan ke Kalimantan, pastinya daerah Kalimantan akan berkembang, dan akan ada perkembangan dalam bidang infrastruktur dan pembangunan. Maka pembangunan pada lahan gambut menjadi fokus yang perlu diperhatikan dan dimanfaatkan peluangnya bagi orang-orang yang mendalami dunia Teknik Sipil.

\section{Stone Column}

Penurunan terjadi akibat proses keluarnya air pori dari dalam massa tanah karena suatu pembebanan. Untuk lapisan tanah kohesif seperti lempung keluarnya air pori memerlukan waktu lama· dan juga penurunan relatif besar, karena mempunyai sifat kompresibel.

Besarnya penurunan dengan dipasangnya stone column adalah perkalian faktor reduksi dengan penurunan total tanah dasar. (Suherman, 1992)

Koefisien reduksi n dinyatakan:

$$
n=\frac{1}{1+\frac{A C}{A}(R-1)}
$$

dengan $\mathrm{n}$ = angka reduksi penurunan stone column, $\mathrm{Ac}=$ luas penampang stone column, $\mathrm{A}=$ luas penampang ekivalen

$$
\mathrm{Sc}=\frac{1}{n} x S t
$$

dengan Sc = besarnya penurunan stone column, $\mathrm{St}=$ besarnya penurunan tanah dasar

\section{Cerucuk Kayu}

Peningkatan kuat geser tanah selalu diikuti dengan semakin kecil nilai angka pori (e) dan bertambahnya kepadatan tanah akibat dari bertambahnya tegangan efektif yang terjadi pada tanah tersebut.

Semakin besar tegangan yang bekerja pada tanah maka nilai angka pori semakin kecil. Dengan menganggap volume cerucuk yang dimasukkan kedalam lapisan lempung lunak merupakan butiran tanah (Vs) dan tanah dianggap material tidak mampu mampat maka akan mengalami perubahan nilai angka pori sebagai berikut (Rusdiansyah, 2016):

$$
\Delta \mathrm{e}=1 /\left(1+\mathrm{V}_{\mathrm{c}}\right)-1
$$

dengan $\Delta \mathrm{e}=$ perubahan angka pori adanya penambahan volume cerucuk, $\mathrm{V}=$ volume awal total tanah sebelum ada cerucuk, $\mathrm{V}_{\mathrm{s}}=$ volume butir awal sebelum ada cerucuk, $\mathrm{V}_{\mathrm{c}}=$ volume cerucuk

\section{Micropiles}

Penurunan pada micropile akan dianggap sebagai penurunan dengan perubahan angka pori akibat pertambahan beban vertikal yang dapat dihitung sebagai berikut (FHWA NHI-05-039 , 2005):

$$
\begin{aligned}
& \Delta \sigma=\frac{Q_{g}}{\left(B_{g}+z\right)\left(L_{g}+z\right)} \\
& \Delta \sigma^{\prime}=\Delta \sigma+Q_{g}
\end{aligned}
$$

dengan $\Delta \sigma=$ tambahan tegangan vertikal ditengah-tengah lapisan yang ditinjau, $\Delta \sigma^{\prime}=$ tambahan tegangan vertikal efektif, $\mathrm{L}_{\mathrm{g}}=$ panjang tiang kelompok, $\mathrm{B}_{\mathrm{g}}=$ lebar tiang kelompok, $\mathrm{Z}=$ jarak dari $\mathrm{z}=0$ ke tengah lapisan tanah 


\section{METODE PENELITIAN}

Dalam penelitian ini, terdapat beberapa tahapan yang dapat diuraikan sebagai berikut:

1. Tahapan Pertama adalah studi literatur dan teori yang mendukung penelitian.

2. Tahapan Kedua adalah adalah pencarian terhadap data tanah dan referensi terhadap asumsi yang akan digunakan.

3. Tahapan Ketiga adalah melakukan korelasi terhadap data tanah dengan rumus yang ditemukan pada tahap pertama

4. Tahapan Keempat adalah menganalisis kebutuhan gaya luar yang terjadi dengan berbagai asumsi.

5. Tahapan Kelima adalah menganalisis metode terbaik diantara ketiga metode yaitu stone column, cerucuk kayu, dan micropile dan menentukan yang terbaik.

6. Tahapan Keenam adalah melakukan trial and error pada metode terbaik untuk mendapat spesifikasi yang terbaik.

\section{HASIL DAN PEMBAHASAN}

Pada penelitian ini, digunakan tanah yang berlokasi di Kalimantan Tengah, Indonesia. Data tanah berupa hasil laboratorium yang sudah siap digunakan untuk perhitungan, hanya saja membutuhkan beberapa korelasi serperti yang disajikan pada Tabel 1 .

Tabel 1 Parameter Tanah Rekapitulasi (Matthew \& Makarim, 2020)

\begin{tabular}{|c|c|c|c|c|c|c|c|c|}
\hline Parameter & Simbol & Unit & Gambut & $\begin{array}{l}\text { Silty } \\
\text { Clay }\end{array}$ & $\begin{array}{l}\text { Clayed } \\
\text { Silt }\end{array}$ & Sandy Clay & $\begin{array}{l}\text { Cemented } \\
\text { Silt }\end{array}$ & $\begin{array}{l}\text { Sandy } \\
\text { Silt }\end{array}$ \\
\hline Depth & $\mathrm{h}$ & $\mathrm{m}$ & $\begin{array}{c}0,00- \\
6,00\end{array}$ & $\begin{array}{l}6,00- \\
12,00\end{array}$ & $\begin{array}{l}12,00- \\
16,00\end{array}$ & $16,00-24,00$ & $\begin{array}{l}24,00- \\
28,00\end{array}$ & $\begin{array}{c}28,00- \\
30,00\end{array}$ \\
\hline Berat Isi & $\gamma$ & $\mathrm{kN} / \mathrm{m}^{3}$ & 11 & 17 & 17 & 17 & 18 & 19,5 \\
\hline Indeks Plastisitas & Ip & $\%$ & 65 & 32 & 32 & 78 & 78 & 78 \\
\hline Kuat Geser Undrained & $\mathrm{C}_{\mathrm{u}}$ & $\mathrm{kPa}$ & 40 & 70 & 90 & 100 & 130 & 110 \\
\hline Angka Pori & $\mathrm{e}_{\mathrm{o}}$ & - & 10 & 1,2 & 1,2 & 1,2 & 0,8 & 0,8 \\
\hline Indeks Kompresi & $\mathrm{C}_{\mathrm{c}}$ & - & 0,6 & 0,44 & 0,44 & 0,44 & 0,36 & 0,36 \\
\hline Indeks Rekompresi & $\mathrm{C}_{\mathrm{s}}$ & - & 0,08 & 0,074 & 0,074 & 0,074 & 0,056 & 0,056 \\
\hline Indeks Kembang & $\mathrm{C}_{\mathrm{r}}$ & - & 0,09 & 0,07 & 0,07 & 0,07 & 0,05 & 0,05 \\
\hline Koefisien Konsolidasi & $\mathrm{C}_{\mathrm{v}}$ & $\mathrm{m}^{2} / \mathrm{s}$ & $1,8 \mathrm{E}-6$ & $1,0 \mathrm{E}-6$ & $1,4 \mathrm{E}-06$ & 1,9E-06 & 1,6E-06 & $1,4 \mathrm{E}-06$ \\
\hline $\begin{array}{l}\text { Koefisien Kompresi } \\
\text { Sekunder }\end{array}$ & $\mathrm{C}_{\alpha}$ & - & 0,036 & 0,0264 & 0,0264 & 0,0264 & 0,0216 & 0,0216 \\
\hline $\begin{array}{c}\text { Rasio Terkonsolidasi } \\
\text { Lebih }\end{array}$ & OCR & - & 5 & 3 & 1,5 & 1,3 & 1,2 & 1,1 \\
\hline Sudut Geser Dalam & $\Phi^{\prime}$ & $\circ$ & 33 & 35 & 35 & 35 & 37,5 & 37,5 \\
\hline
\end{tabular}

Beban yang di analisis berupa konstruksi jalan yang desain perkerasannya didapat dari Tugas Akhir yang berjudul "Perencanaan Tebal Perkerasan Lentur Dan Rencana Anggaran Biaya Pada Ruas Jalan Tol Seksi 4 Balikpapan Samarinda Kalimantan Timur” dari Politeknik Negeri Samarinda yang ditulis pada tahun 2018. (Saputro, 2018) Didapatkan hasil seperti yang disajikan pada Tabel 2:

Tabel 2 Tegangan Vertikal Akibat Beban Perkerasan Jalan Tol

\begin{tabular}{ccc}
\hline \multirow{2}{*}{ Lapisan } & \multicolumn{2}{c}{$\Delta \sigma^{\prime}\left(\mathrm{kN} / \mathrm{m}^{2}\right)$} \\
\cline { 2 - 3 } & Sisi Pergi & Sisi Datang \\
\hline$(0-6 \mathrm{~m})$ & 8,8945 & 9,0203 \\
$(6-12 \mathrm{~m})$ & 6,2513 & 6,3976 \\
$(12-16 \mathrm{~m})$ & 5,6610 & 5,8250 \\
$(16-24 \mathrm{~m})$ & 3,8565 & 3,9892 \\
$(24-28 \mathrm{~m})$ & 3,1262 & 3,2448 \\
$(28-30 \mathrm{~m})$ & 2,6579 & 2,7643 \\
\hline
\end{tabular}


Analisis Perbandingan Metode Perbaikan Tanah pada

Renaldo Arisugan, et al. Konstruksi Jalan Tol di Atas Tanah Gambut

Data Stone Column:

Pola Pemasangan Kotak

$\mathrm{s}=1 \mathrm{~m}$

$D_{w}=1,13 \times \mathrm{s}=1,13 \times 1=1,13 \mathrm{~m}$

$\mathrm{C}_{1}=0,7854$

$\mathrm{D}=0,8 \mathrm{~m}$

$\varnothing=35^{\circ}$

$\gamma=11 \mathrm{kN} / \mathrm{m}^{3}$

$\mathrm{H}=6 \mathrm{~m}$

Ac $=\frac{\pi}{4} D^{2}=\frac{\pi}{4} 0,8^{2}=0,5027$

$\mathrm{A}=\frac{\pi}{4} D_{w}{ }^{2}=\frac{\pi}{4} 1,13^{2}=1,0029$

$\mathrm{Ec}=120.000 \mathrm{kN} / \mathrm{m}^{2}$

$\mathrm{Es}=3.200 \mathrm{kN} / \mathrm{m}^{2}$

$\mathrm{n}=\frac{1}{1+\left(\frac{A C}{A}\right)(R-1)}=\frac{1}{1+\left(\frac{0,5027}{1,0029}\right)\left(\frac{120.000}{3.200}-1\right)}=0,0518$

Penurunan Setelah Dipasang Stone Column

$S_{p(\text { stone column })}=S_{p} \times n=0,0263 \times 0,0518=0,0014$

$S_{\text {S (stone column })}=S_{S} \times n=0,0378 \times 0,0518=0,0020$

Berikut hasil penurunan setelah dipasang stone column seperti yang disajikan pada Tabel 3:

Tabel 3 Penurunan setelah dipasang stone column

\begin{tabular}{rccrrr}
\hline \multirow{2}{*}{ Lapisan } & \multirow{2}{*}{$S_{e}(\mathrm{~m})$} & \multicolumn{2}{c}{$S_{p}(\mathrm{~m})$} & \multicolumn{2}{c}{$S_{s}(\mathrm{~m})$} \\
\cline { 3 - 6 } & & Sisi Datang & Sisi Pergi & Sisi Datang & Sisi Pergi \\
\hline$(0-6 \mathrm{~m})$ & 0,0054 & 0,0014 & 0,0014 & 0,0020 & 0,0020 \\
$(6-12 \mathrm{~m})$ & - & 0,0186 & 0,0183 & 0,1177 & 0,1177 \\
$(12-16 \mathrm{~m})$ & - & 0,0052 & 0,0051 & 0,1020 & 0,1020 \\
$(16-24 \mathrm{~m})$ & - & 0,0044 & 0,0043 & 0,1574 & 0,1574 \\
$(24-28 \mathrm{~m})$ & - & 0,0012 & 0,0011 & 0,1042 & 0,1042 \\
$(28-30 \mathrm{~m})$ & - & 0,0004 & 0,0004 & 0,0649 & 0,0649 \\
\hline$\Sigma$ & 0,0054 & 0,0312 & 0,0305 & 0,5481 & 0,5481 \\
\hline \multicolumn{5}{c}{ SUM } &
\end{tabular}

Data cerucuk kayu:

Jenis Kayu = Ulin

$\mathrm{D}=0,1 \mathrm{~m}$

$\mathrm{H}=4 \mathrm{~m}$

$\mathrm{V}_{\mathrm{c}}=\frac{\pi}{4} D^{2} \times H=\frac{\pi}{4} 0,1^{2} \times 4=0,0314$

$\Delta e=\frac{1}{\left(1+V_{c}\right)}-1=\frac{1}{(1+0,0314)}-1=0,0305$

Untuk Sisi Datang:

$e_{1}=e_{p}$

$e_{2}=e_{1}-\Delta e=9,6383-0,0305=9,6079$

$C_{c}=\frac{e_{1}-e_{2}}{\Delta \sigma^{\prime}}=\frac{9,6383-9,6079}{9,0203}=0,003377$

$S_{s}=\frac{C_{c} H}{1+e_{2}} \log \log \left(\frac{t_{2}}{t_{1}}\right)=\frac{0,003377 \times 6}{1+9,6079} \log \log \left(\frac{39,460}{0,5397}\right)=0,0036 \mathrm{~m}$

Untuk Sisi Pergi:

$e_{1}=e_{p}$

$e_{2}=e_{1}-\Delta e=9,6411-0,0305=9,6106$ 
$C_{c}=\frac{e_{1}-e_{2}}{\Delta \sigma^{\prime}}=\frac{9,6411-9,6106}{8,8945}=0,003425$

$S_{s}=\frac{C_{c} H}{1+e_{2}} \log \left(\frac{t_{2}}{t_{1}}\right)=\frac{0,003425 \times 6}{1+9,6106} \log \left(\frac{39,460}{0,5397}\right)=0,0036 m$

Berikut hasil penurunan setelah dipasang cerucuk kayu seperti yang disajikan pada Tabel 4:

Tabel 4 Penurunan setelah dipasang cerucuk kayu

\begin{tabular}{|c|c|c|c|c|c|c|}
\hline \multirow[b]{2}{*}{ Lapisan } & \multirow[b]{2}{*}{$\mathrm{Z}(\mathrm{m})$} & \multirow[b]{2}{*}{$S_{e}(\mathrm{~m})$} & \multicolumn{2}{|c|}{$S_{p}(\mathrm{~m})$} & \multicolumn{2}{|c|}{$S_{S}(\mathrm{~m})$} \\
\hline & & & Sisi Datang & Sisi Pergi & Sisi Datang & Sisi Pergi \\
\hline$(0-6 m)$ & 7 & 0,0054 & 0,0263 & 0,0261 & 0,0036 & 0,0036 \\
\hline$(6-12 m)$ & 13 & - & 0,0186 & 0,0183 & 0,1177 & 0,1177 \\
\hline$(12-16 m)$ & 18 & - & 0,0052 & 0,0051 & 0,1020 & 0,1020 \\
\hline$(16-24 m)$ & 24 & - & 0,0044 & 0,0043 & 0,1574 & 0,1574 \\
\hline$(24-28 m)$ & 30 & - & 0,0012 & 0,0011 & 0,1042 & 0,1041 \\
\hline \multirow[t]{3}{*}{$(28-30 \mathrm{~m})$} & 33 & - & 0,0004 & 0,0004 & 0,0649 & 0,0649 \\
\hline & $\Sigma$ & 0,0054 & 0,0562 & 0,0553 & 0,5497 & 0,5497 \\
\hline & SUM & & & 1,2163 & & \\
\hline
\end{tabular}

Data Micropile:

$\mathrm{fc}^{\prime}=25 \mathrm{MPa}$

$\mathrm{fy}_{\text {casing }}=235 \mathrm{MPa}$

$\mathrm{fy}_{\mathrm{bar}}=400 \mathrm{MPa}$

$\mathrm{OD}=165,2 \mathrm{~mm}$

$\mathrm{t}_{\mathrm{w}}=6 \mathrm{~mm}$

$\mathrm{D}_{\text {tulangan }}=13 \mathrm{~mm}$

$\mathrm{D}_{\mathrm{n}}=200 \mathrm{~mm}$

Penurunan pada micropile akan dianggap sebagai penurunan dengan perubahan angka pori akibat pertambahan beban vertikal yang dapat dihitung sebagai berikut:

$\sigma_{o}^{\prime}=3 \mathrm{kN} / \mathrm{m}^{2}$

$Q_{g}=9,0203 \mathrm{kN} / \mathrm{m}^{2}$

$\mathrm{n}$ (jumlah baris) $=1$

$\mathrm{m}($ jumlah kolom $)=10$

$\mathrm{s}($ jarak antar tiang) $=1 \mathrm{~m}$

$L_{g}=\left(D_{n} \times m\right)+((m-1) \times s)=(0,2 \times 10)+((10-1) \times 1)=11 m$

$B_{g}=\left(D_{n} \times n\right)+((n-1) \times s)=(0,2 \times 1)+((1-1) \times 1)=0,2 m$

$\mathrm{z}=3 \mathrm{~m}$

$\mathrm{H}=6 \mathrm{~m}$

Untuk Sisi Datang:

$\Delta \sigma=\frac{Q_{g}}{\left(B_{g}+z\right)\left(L_{g}+z\right)}=\frac{9,0203}{(11+3)(0,2+3)}=0,20135 \mathrm{kN} / \mathrm{m}^{2}$

$\Delta \sigma^{\prime}=\Delta \sigma+Q_{g}=9,0202+0,20135=9,22155 \mathrm{kN} / \mathrm{m}^{2}$ 
$\Delta e=C_{c} \log \left(\frac{\sigma_{o}^{\prime}+\Delta \sigma^{\prime}}{\sigma^{\prime}{ }_{o}}\right)=0,6 \log \left(\frac{3+9,22155}{3}\right)=0,366$

$e_{2}=e_{0}-\Delta e=10-0,366=9,634$

$C_{c}=\frac{e_{1}-e_{2}}{\Delta \sigma^{\prime}}=\frac{9,6383-9,634}{9,22155}=0,000469$

$S_{s}=\frac{C_{c} H}{1+e_{2}} \log \log \left(\frac{t_{2}}{t_{1}}\right)=\frac{0,000469 \times 6}{1+9,634} \log \log \left(\frac{39,460}{0,5397}\right)=0,0005 \mathrm{~m}$

Untuk Sisi Pergi:

$\Delta \sigma=\frac{Q_{g}}{\left(B_{g}+z\right)\left(L_{g}+z\right)}=\frac{8,8945}{(11+3)(0,2+3)}=0,19854 \mathrm{kN} / \mathrm{m}^{2}$

$\Delta \sigma^{\prime}=\Delta \sigma+Q_{g}=8,8945+0,19854=9,09304 \mathrm{kN} / \mathrm{m}^{2}$

$\Delta e=C_{c} \log \log \left(\frac{\sigma_{o}^{\prime}+\Delta \sigma^{\prime}}{\sigma^{\prime}{ }_{o}}\right)=0,6 \log \log \left(\frac{3+9,09304}{3}\right)=0,3632$

$e_{2}=e_{0}-\Delta e=10-0,3632=9,6368$

$C_{c}=\frac{e_{1}-e_{2}}{\Delta \sigma^{\prime}}=\frac{9,6411-9,6368}{9,09304}=0,000474$

$S_{s}=\frac{C_{c} H}{1+e_{2}} \log \log \left(\frac{t_{2}}{t_{1}}\right)=\frac{0,000474 \times 6}{1+9,6368} \log \log \left(\frac{39,460}{0,5397}\right)=0,0005 \mathrm{~m}$

Berikut hasil penurunan setelah dipasang micropile seperti yang disajikan pada Tabel 5:

Tabel 5 Penurunan setelah dipasang micropile

\begin{tabular}{|c|c|c|c|c|c|c|}
\hline \multirow[b]{2}{*}{ Lapisan } & \multirow[b]{2}{*}{$\mathrm{Z}(\mathrm{m})$} & \multirow[b]{2}{*}{$S_{e}(\mathrm{~m})$} & \multicolumn{2}{|c|}{$S_{p}(\mathrm{~m})$} & \multicolumn{2}{|c|}{$S_{S}(\mathrm{~m})$} \\
\hline & & & Sisi Datang & Sisi Pergi & Sisi Datang & Sisi Pergi \\
\hline$(0-6 m)$ & 7 & 0,0054 & 0,0263 & 0,0261 & 0,0005 & 0,0005 \\
\hline$(6-12 m)$ & 13 & - & 0,0186 & 0,0183 & 0,1177 & 0,1177 \\
\hline$(12-16 m)$ & 18 & - & 0,0052 & 0,0051 & 0,1020 & 0,1020 \\
\hline$(16-24 m)$ & 24 & - & 0,0044 & 0,0043 & 0,1574 & 0,1574 \\
\hline (24-28m) & 30 & - & 0,0012 & 0,0011 & 0,1042 & 0,1041 \\
\hline \multirow[t]{3}{*}{$(28-30 m)$} & 33 & - & 0,0004 & 0,0004 & 0,0649 & 0,0649 \\
\hline & $\Sigma$ & 0,0054 & 0,0562 & 0,0553 & 0,5467 & 0,5466 \\
\hline & SUM & & & 1,2102 & & \\
\hline
\end{tabular}




\section{Total Penurunan}

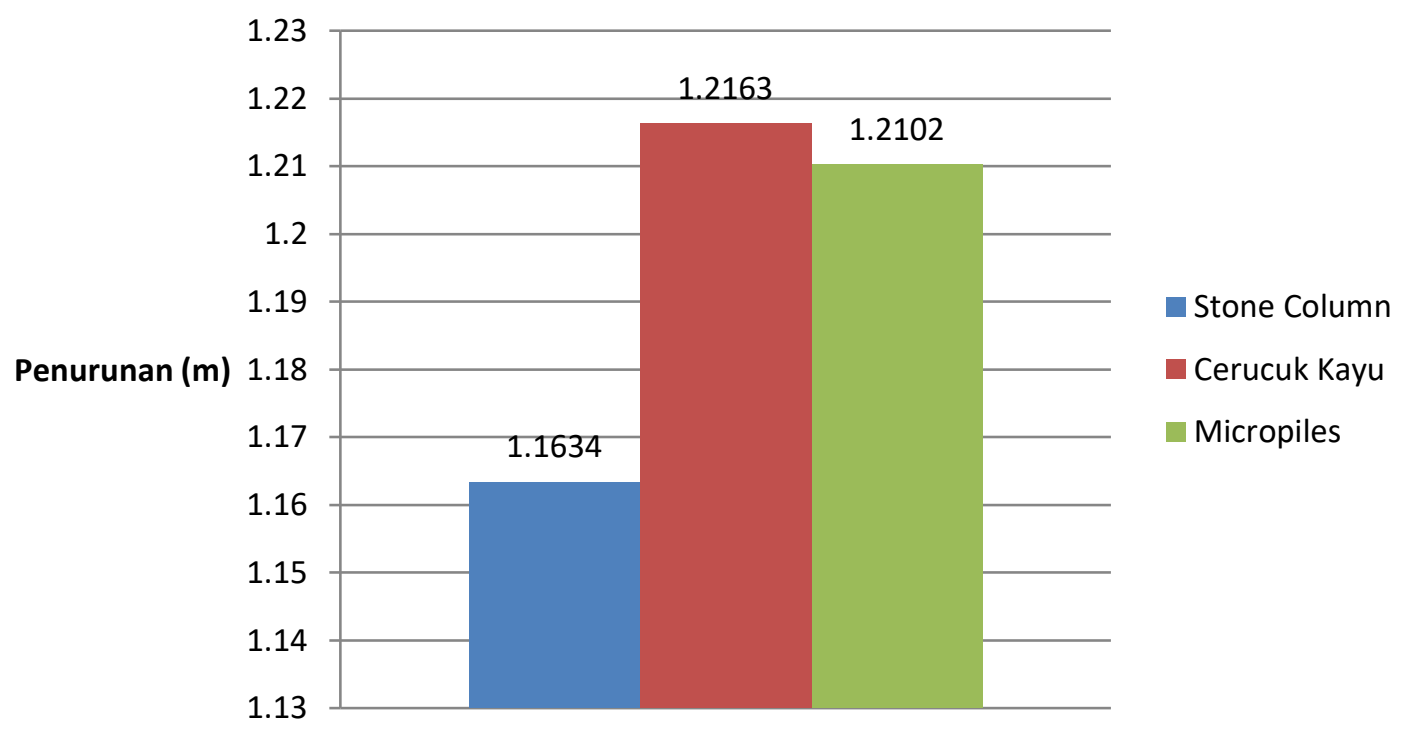

Gambar 1 Diagram Hasil Akhir Penurunan

Pada penelitian ini didapat metode perbaikan tanah dengan stone column memiliki angka penurunan terkecil seperti yang disajikan pada Gambar 1, maka akan dicari spesifikasi terbaik dari metode stone column.

Percobaan dilakukan dengan mengubah diameter dan jarak antar stone column dengan ketinggian yang tetap sama.

Dicoba pola pemasangan kotak seperti yang disajikan pada Tabel 6:

Tabel 6 Percobaan pemasangan stone column dengan pola pemasangan kotak

\begin{tabular}{ccccccc}
\hline Pola & \multicolumn{7}{c}{ Kotak } \\
\hline D (m) & & 0,9 & & & 1 & \\
S (m) & 0,95 & 1 & 1,05 & 1,05 & 1,1 & 1,15 \\
St Malang (m) & 0,5812 & 0,5814 & 0,5817 & 0,5812 & 0,5814 & 0,5816 \\
St Pandaan (m) & 0,5804 & 0,5806 & 0,5809 & 0,5803 & 0,5806 & 0,5808 \\
Total Penurunan (m) & 1,1616 & 1,1620 & 1,1626 & 1,1615 & 1,1620 & 1,1624 \\
\hline
\end{tabular}

Dicoba pola pemasangan segitiga seperti yang disajikan pada Tabel 7:

Tabel 7 Percobaan pemasangan stone column dengan pola pemasangan segitiga

\begin{tabular}{ccccccc}
\hline Pola (m) & \multicolumn{7}{c}{ Segitiga } \\
\hline D (m) & 0,95 & 1 & 1,05 & 1,05 & 1,1 & 1,15 \\
S (m) & 0,95 & 0,5813 & 0,5809 & 0,581 & 0,5813 \\
St Malang (m) & 0,5809 & 0,5811 & 0,5813 & \\
St Pandaan (m) & 0,5800 & 0,5803 & 0,5805 & 0,5800 & 0,5802 & 0,5804 \\
Total Penurunan (m) & 1,1609 & 1,1614 & 1,1618 & 1,1609 & 1,1612 & 1,1617 \\
\hline
\end{tabular}

Setelah dilakukan trial and error maka didapat penurunan terkecil yaitu sebesar 1,1609 m. Sehingga agar jalan tol dapat tetap berada di level $\pm 0,00$, maka tanah harus ditimbun setinggi minimal 1,1609 m dengan material tertentu sebelum dibangun jalan tol. Penimbunan dapat dilakukan dengan berbagai macam material seperti pasir urug atau tanah urug, disesuaikan dengan kebutuhan beban perkerasan. Disesuaikan dengan beban perkerasan, maka jenis 
timbunan yang akan digunakan adalah timbunan pilihan dengan material yang digunakan adalah tanah berpasir (sandy clay).

\section{KESIMPULAN DAN SARAN}

\section{Kesimpulan}

1. Hasil analisis metode perbaikan tanah yang diantaranya stone column, cerucuk kayu, dan micropile, didapat metode yang terbaik adalah stone column dengan total penurunan terkecil yaitu 1,1634 m.

2. Peningkatan ukuran diameter stone column harus seimbang dengan ukuran jarak antar stone column untuk memaksimalkan penurunan.

3. Pada percobaan berbagai ukuran pada metode stone column didapat hasil penurunan terkecil yaitu 1,1609 m dengan pola pemasangan segitiga, diameter $1 \mathrm{~m}$ dan dengan jarak antar kolom sebesar 1,05 m.

4. Penurunan yang terjadi merupakan penurunan tanah eksisting, sehingga perlu dilakukan penimbunan berupa material tanah berpasir (sandy clay) setinggi minimal 1,1609 m agar tanah eksisting dapat berada di $\pm 0,00$ sebelum dibangun jalan tol.

5. Tanah gambut berupa material tanah yang sangat berongga karena memiliki void ratio yang sangat tinggi dibanding jenis tanah lain.

\section{Saran}

1. Metode perbaikan pada lapisan tanah gambut dapat mengurangi besar penurunan total.

2. Karena karakteristik tanah gambut yang memiliki kadar air yang tinggi, dan sangat berpori, pemilihan metode perbaikan dapat dipersempit kepada metode yang bertujuan mengurangi kadar air seperti vertical drain dan kompaksi atau mengisi pori seperti grouting.

3. Karena tanah gambut mengandung material organik yang tinggi dengan tingkat dekomposisi yang beragam maka banyak ketidakpastian dalam menentukan penurunan yang akurat, maka dari itu di sarankan melakukan tes laboratorium untuk memperoleh besar penurunan yang akurat.

4. Perbaikan tanah dapat digabungkan dengan metode goetextile, geomembrane, atau geogrid.

5. Untuk konstruksi jalan tol di atas tanah gambut seharusnya penggunaan timbunan di manfaatkan sebagai prapembebanan, bukan hanya penambahan elevasi saja.

\section{DAFTAR PUSTAKA}

FHWA NHI-05-039 . (2005). Micropile Design and Construction. United States: U.S. Department of Transportation Federal Highway Administration.

Global Wetlands. (2019). Global Wetlands. Diakses Maret, 2021, from www2.cifor.org: https://www2.cifor.org/global-wetlands/

Matthew, C., \& Makarim, C. A. (2020). Analisis Timbunan di Atas Lapisan Tanah Gambut. JMTS: Jurnal Mitra Teknik Sipil , 323-336.

Rusdiansyah. (2016). Asumsi Sistem Cerucuk sebagai Alternatif Solusi dalam Penanganan Kelongsoran Lereng Jalan di Atas Tanah Lunak. Prosiding Seminar Nasional Geoteknik, 250-278.

Saputro, W. T. (2018). Perencanaan Tebal Perkerasan Lentur dan Rencana Anggaran Biaya pada Ruas Jalan Tol Seksi 4 Balikpapan - Samarinda Kalimantan Timur. Samarinda: Politeknik Negeri Samarinda.

Suherman, D. (1992). Laporan penelitian: "Perilaku Stone Column". Bandung: Kementrian Pekerjaan Umum dan Perumahan Rakyat.

TEMPO.CO. (2019). Jokowi Pimpin Rapat Matangkan Rencana Pemindahan Ibu Kota. Dipetik Maret 8, 2021, dari nasional.tempo.co: https://nasional.tempo.co/read/1200301/jokowi-pimpin-rapat-matangkan-rencanapemindahan-ibu-kota/full\&view $=$ ok 